Review

\title{
Research Progress on Vertebrobasilar Dolichoectasia
}

\author{
Yong-Jie Yuan*, Kan Xu*, Qi Luo, Jin-Lu Yu ${ }^{\varpi}$ \\ Department of Neurosurgery, Jilin University First Hospital, Changchun 130021, China. \\ * Yong-Jie Yuan and Kan Xu contributed equally to the work.
}

$\triangle$ Corresponding author: Jin-Lu Yu and Qi Luo, Department of Neurosurgery, Jilin University First Hospital, Changchun 130021, China. Tel: +86-431-88782264. Email: jlyu@jlu.edu.cn.

(C) Ivyspring International Publisher. This is an open-access article distributed under the terms of the Creative Commons License (http://creativecommons.org/ licenses/by-nc-nd/3.0/). Reproduction is permitted for personal, noncommercial use, provided that the article is in whole, unmodified, and properly cited.

Received: 2014.01.13; Accepted: 2014.07.21; Published: 2014.08.02

\begin{abstract}
Vertebrobasilar dolichoectasia (VBD) is a rare disease characterized by significant expansion, elongation, and tortuosity of the vertebrobasilar arteries. Current data regarding VBD are very limited. Here we systematically review VBD incidence, etiology, characteristics, clinical manifestations, treatment strategies, and prognosis. The exact incidence rate of VBD remains unclear, but is estimated to be $1.3 \%$ of the population. The occurrence of VBD is thought to be due to the cooperation of multiple factors, including congenital factors, infections and immune status, and degenerative diseases. The VBD clinical manifestations are complex with ischemic stroke as the most common, followed by progressive compression of cranial nerves and the brain stem, cerebral hemorrhage, and hydrocephalus. Treatment of VBD remains difficult. Currently, there are no precise and effective treatments, and available treatments mainly target the complications of VBD. With the development of stent technology, however, it may become an effective treatment for VBD.
\end{abstract}

Key words: vertebrobasilar dolichoectasia; etiology; clinical manifestations; imaging; treatment strategies.

\section{VBD Overview}

Vertebrobasilar dolichoectasia (VBD) is a rare disease characterized by significant expansion, elongation, and tortuosity of the vertebrobasilar arteries. Although there is no current data on the exact incidence of VBD in the general population, angiography and autopsy results suggest that the overall incidence is less than $0.05 \%$ [1]. However, it has also been found that VBD incidence varies among specific populations. Ince et al. showed that VBD occurs in approximately $2.06 \%$ of the first-ever stroke population [2]. Kumral et al. showed that VBD incidence is $3.7 \%$ in patients with posterior circulation infarcts [3]. A study in Japan revealed that among people undergoing routine MRI and MRA examinations, the asymptomatic VBD incidence rate is $1.3 \%{ }^{[4]}$. Therefore, VBD incidence remains unclear and requires further investigation.

\section{Etiology of VBD}

Although VBD etiology is not entirely clear, several possible mechanisms have been proposed:

\section{Hypertension-induced atherosclerosis}

Because VBD is commonly observed in older male hypertensive patients, a long-existing hypothesis is that hypertension-induced atherosclerosis is a major factor contributing to VBD occurrence [5]. However, this assumption is flawed because not all VBD patients, particularly children and adolescents, have atherosclerosis $[5,6]$. In these cases, histopathological examination revealed widespread defects and fractures of the internal elastic lamina of the dolichoectatic arteries, which were secondary to smooth muscle atrophy and reticular fiber deficiency $[6,7]$ and differed from typical atherosclerotic lesions $[6,8]$. Considering that atherosclerosis and hypertension are commonly observed in contrast to the very low VBD 
incidence, atherosclerosis is unlikely to be the main causative factor of VBD. Pico et al. also found no correlation between arterial dolichoectasia and atherosclerosis ${ }^{[9]}$. It has even been suggested that atherosclerosis results from morphological and hemodynamic changes induced by VBD, which again disagrees with the hypothesis that atherosclerosis leads to $\operatorname{VBD}[6,10]$

\section{Congenital factors}

Reports regarding the association of VBD with some congenital diseases are not uncommon. Schievink et al. found that VBD incidence was $2.3 \%$ in 307 cases of autosomal recessive polycystic kidney disease (ARPKD) whereas no VBD occurred in 360 cases of autosomal dominant polycystic kidney disease (ADPKD) ${ }^{[11]}$. Laforet et al. reported three patients with combined Pompe disease and VBD, two of whom were sisters [12]. Garzuly et al. reported a family with Fabry disease due to a novel mutation in the $\alpha$-galactosidase A (GLA) gene, and all six family members were diagnosed with VBD [13]. A controlled retrospective study of 47 pediatric patients with sickle cell anemia indicated that $37 \%$ of the patients had VBD [14]. In addition, Hainsworth et al. reported a case of a 22-year-old woman with combined Marfan syndrome and giant basilar artery aneurysm [15]. Kim et al. reported one case of Ehlers-Danlos syndrome associated with cervical nerve root compression caused by left vertebral artery dolichoectasia [16]. Baccin et al. reported two cases of PHACES syndrome associated with intracranial arterial dolichoectasia [17]. Khan et al. reported two cases of internal carotid artery dilation combined with moyamoya disease, patent ductus arteriosus, and pupillary function disorder, and speculated that this might be a clinical syndrome related to genetic factors [18]. Flemming et al. identified abdominal aortic aneurysms in $29(18 \%)$ of 159 VBD patients [1]. This evidence supports the notion that VBD could be a congenital disease.

\section{Other factors}

The occurrence of VBD may also be related to infection, including syphilis infection. Dalton et al. reported a case of combined varicella-zoster virus infection with advanced Hodgkin's lymphoma in which MRA examination indicated dolichoectasia of vertebrobasilar arteries, bilateral carotid arteries, M1 segments of bilateral middle cerebral arteries, as well as the A1 segment of the right anterior cerebral artery [19]. Mahadevan et al. reported a case of an AIDS patient with fusiform vertebrobasilar aneurysms [20]. Lodder et al. reported a case of VBD caused by syphilis infection [21]. Abnormal matrix metalloproteinase (MMP) expression might also be another cause of
VBD. Laforet et al. showed that the genotype and serum levels of MMPs were associated with intracranial arterial dilation, and MMP-3 played a potentially important role in intracranial artery dilation [22]. Toyoshima et al. proposed that VBD is an Ig-G4-related immune disease [23]. VBD may result from the progression of fusiform aneurysms or arterial dissections, or by itself as a giant dissection [24, 25]. Taken together, the data suggest that the occurrence of VBD may be due to the combined effect of congenital and acquired factors ${ }^{[6,26]}$.

\section{Clinical manifestations}

VBD can develop without any clinical symptoms. In cases with obvious symptoms, clinical manifestations vary widely. The most common symptom is ischemic stroke, followed by brainstem and cranial nerve compression, hydrocephalus, and cerebral hemorrhage [1, 27]. In a prospective study of 156 patients with VBD for an average follow-up period of 11.7 years, ischemic stroke occurred in 59 cases $(37.8 \%)$, cranial nerve and brainstem compression occurred in 31 cases $(19.9 \%)$, cerebral hemorrhage occurred in 21 cases (13.5\%), and hydrocephalus occurred in 2 cases $(1.3 \%)$ [27].

\section{Ischemic stroke}

The most common clinical symptom of VBD is ischemic stroke, and is also the most common cause of VBD-related death [1]. Passero et al. studied the location of ischemic stroke and found that infarcts in the brainstem accounted for $41 \%$, followed by posterior cerebral artery territory (29\%), thalamus (22\%), cerebellum $(2 \%)$, and other regions (2\%). Of these infarcts, $66 \%$ were lacunar infarction whereas $34 \%$ were massive cerebral infarction [27]. The recurrence risk of ischemic stroke in VBD patients is high. Flemming et al. reported that the recurrence rate of ischemic stroke was $6.7 \%$ (per person per year) ${ }^{[1]}$. Recurrent ischemic stroke is indicative of poor prognosis. Flemming et al. reported a case of recurrent ischemic stroke in which the patient died from subarachnoid hemorrhage after 5 days ${ }^{[28]}$. The pathogenesis of ischemic stroke in VBD includes the following features [1,3, 6, 27]: (1) In VBD, the vertebrobasilar blood flow is two-way with reduced forward flow. Although ultrasonic flow suggests peak velocity remains relatively constant, mean velocity is reduced. Reduced blood flow can cause hypoperfusion in the blood supply area, leading to ischemic symptoms. (2) Reduced blood flow in dilated arteries can cause intraluminal thrombosis, which flows into the distal vessels or obstructs the opening of perforating arteries to form infarction. (3) Hemodynamic changes in vertebrobasilar arteries can cause endothelial injury and the formation of atherosclerosis. 
Plaques that peel off can block blood vessels. (4) Dolichoectasia of vertebrobasilar arteries leads to pulling and twisting of the branching vessels, particularly those of the basilar arteries, causing cerebral infarction due to decreased blood flow in the perforating arteries. Thus, vertebrobasilar shift is more likely to cause contralateral infarction.

\section{Brainstem and peripheral nerve compression}

The mass effect of VBD can compress the nearby brainstem and cranial nerves, leading to symptoms such as weakness, dizziness, choking on water, cranial nerve damage, neurogenic hypertension, or pseudo space-occupying lesions within cranial fossa [4, 6, 29-31].

(1) Brainstem compression: Due to its gradually progressive nature, the course of brainstem compression by VBD is usually slow. Although sometimes the mass effect of VBD can be very serious, the brainstem can gradually tolerate compression without showing obvious clinical symptoms. Nevertheless, some minor nerve damage can be detected that has important clinical significance [29]. Passero et al. found that the most common subclinical manifestations are extension of the blink reflex latency and changes in motor evoked potentials in limbs. It is recommended that when imaging examination is not feasible, monitoring brainstem auditory evoked potential blink reflexes, and motor evoked potentials can help VBD follow-up and allow timely surgical intervention [32].

(2) Cranial nerve compression: Nearly all cranial nerve damage symptoms can be associated with VBD [32, 33]. The most common symptoms are trigeminal neuralgia and hemifacial spasm, which are caused by VBD pulsatile compression of the trigeminal nerve root and facial nerve root [31,34,35]. For instance, Yang et al. reported 475 patients with trigeminal neuralgia, among which 10 cases (2.1\%) were caused by VBD. These VBD patients obtained good therapeutic effects with microvascular decompression treatment [34]. In addition, VBD can also compress the abducens nerve [36], trochlear nerve [37], and oculomotor nerve [38]. Other nerve compression symptoms such as nystagmus [39], tinnitus [40], hoarseness, and difficulty swallowing ${ }^{[41]}$ have been reported. Additionally, VBD can cause multiple cranial nerve symptoms simultaneously. Madhugiri et al. reported a case of VBD-induced polyneuropathy combined with ADPKD. The patient was given carbamazepine and pregabalin combination therapy and completely recovered from trigeminal neuralgia and hemifacial spasm. Diplopia caused by abducens nerve palsy also remitted spontaneously after one month ${ }^{[42]}$.
(3) Neurogenic hypertension: Neurogenic hypertension caused by VBD mass effects is commonly seen in clinical practice $[4,30,31]$. Ikeda et al. found that hypertension occurred most frequently when VBD compresses the left ventrolateral medulla [4]. This is because the left ventrolateral medulla is the center of sympathetic activities and cardiovascular events. Upon compression, these adrenergic neurons are provoked in a highly active state, thereby causing neurogenic hypertension. Another hypothesis is that VBD compresses the left vagus nerve root zone, resulting in functional blockade of afferent nerve fibers from the ventricular and atrial chambers to the solitary tract nucleus and neurogenic hypertension, further enhancing VBD progression [4,31]. Gizewski et al. reported a case of a VBD patient with resistant hypertension that significantly improved after surgery to block expansion of the left vertebral artery [30]. El-Ghandour et al. also reported successful treatment of drug-resistant hypertension using microvascular decompression in patients who also presented with trigeminal neuralgia [31]. These reports support the notion that VBD can cause neurogenic hypertension.

\section{Obstructive hydrocephalus}

Obstructive hydrocephalus is a rare complication of VBD. It is predominantly due to cerebrospinal fluid circulation disorders caused by direct or indirect compression of the bottom of the third ventricle or midbrain aqueduct. It can be radiographically divided into obstruction-visible and obstruction-invisible hydrocephalus [33,43-47]. Hydrocephalus caused by direct mechanical pressure is relatively rare and imaging shows obvious obstruction [43,45,46]. The proposed mechanism for obstruction-invisible hydrocephalus is a "water hammer" effect within the bottom of the third ventricle or foramina of Monro, which is generated by pulsatile blood flow in the dolichoectatic arteries and results in hydrocephalus under normal pressure ${ }^{[33,44]}$. In line with this hypothesis, Breig et al. reported three cases of VBD-induced hydrocephalus without obvious obstruction of the ventricular system [47].

\section{Hemorrhage}

It was previously thought that VBD rarely incurs hemorrhage because during VBD, a layered thrombus forms along the extended, expanded, and tortuous artery. These clots can play a role in reinforcing the arterial wall and help lower the risk of bleeding [48]. Passero et al., however, found in a follow-up study of 156 VBD patients that VBD-related intracranial hemorrhage was not uncommon during an average 9.35-year follow-up. Twenty-eight patients $(18 \%)$ experienced one or more bleedings and 7 patients died, including 6 cases of subarachnoid hemorrhage (19\%), 
and blood clots were concentrated in the basilar artery pool. Twenty-six ( $81 \%$ ) bleeding events occurred in the cerebrum whereas $85 \%$ of the intracerebral hemorrhages were located in the posterior cerebral circulation area, with branching points of the small blood vessels the most frequent [49]. The extent of hemorrhage is significantly related to VBD severity. In addition, poor control of hypertension and the use of antiplatelet or anticoagulant drugs can also increase the risk of hemorrhage. VBD-associated aneurysm may also contribute [48-51]. Idbaih et al. demonstrated that VBD-related bleeding risk was associated with the extent as well as the speed of arterial dilatation. Thin arterial wall and rapid expansion are signs of VBD deterioration and hemorrhage ${ }^{[52]}$.

\section{Headache}

VBD-caused headaches are rare but are observed in clinical practice. Staikov et al. reported a case of VBD-induced exertional headache. After receiving propranolol treatment, the patient could resume normal movement and the headache disappeared. It was reasoned that his blood pressure increased after exercise, thus stretching the already extended arteries. As a result, perivascular pain fibers were pulled to cause headache. Propranolol exerted negative inotropic and chronotropic action on the heart, lowering blood pressure and reducing blood pressure fluctuation to achieve its therapeutic effect [53].

\section{Imaging features}

Currently, there are no widely accepted quantitative standards for VBD diagnostic imaging. Diagnosis of VBD usually relies on assessment of the patient's vascular images by clinicians and radiologists based on their practical experience, in combination with clinical symptoms. A general consensus agrees that in VBD, the affected vertebrobasilar arteries are longer and broader than normal [6,54].

\section{CT/CTA standards}

The conventional CT standards proposed by Smoker et al. are commonly used as diagnostic imaging criteria. When the basilar artery is beyond the range of the saddleback or slope sections, or the basilar artery bifurcation point is beyond the level of the suprasellar cistern, it can be diagnosed as over-extension. Expansion can be diagnosed when, at any point, the basilar artery diameter is greater than $4.5 \mathrm{~mm}{ }^{[55]}$. Thin layer scans of high-resolution CT can to some extent avoid misdiagnoses caused by petrous bone artifacts, CT angiography (CTA) after three-dimensional reconstruction clearly demonstrates the relationship between blood vessel morphology and bone structure. Nevertheless, infor- mation regarding peripheral nerve structure and hemodynamics is still limited in this method [22].

\section{MRI/MRA standards}

Giang et al. ${ }^{[56]}$ first compared MRI and CT in the diagnosis of VBD and suggested that MRI diagnosed VBD as well as CT; however, MRI is superior to conventional $\mathrm{CT}$ in delineating the anatomical relationship with neural structures and in evaluating coexisting pathology. MRI is particularly useful in cases of hydrocephalus and suspected posterior fossa masses, because it can show VBD impingement upon the third ventricle, brainstem, or cerebellopontine angle and eliminate the possibility of concurrent abnormalities. The MRA standards raised by Ubogu define extension by MRA as the length of basilar artery greater than $29.5 \mathrm{~mm}$ or the vertical distance from the connection of the basilar artery starting point and a bifurcation point greater than $10 \mathrm{~mm}$. For vertebral arteries, if the length is greater than $23.5 \mathrm{~mm}$, or at any point the vertical distance from the connection of the skull entry point and the basilar artery starting point is greater than $10 \mathrm{~mm}$, it is considered extension [57]. However, the morphology, length, and diameter of vertebrobasilar arteries vary in different populations and among males and females. A study by Förster et al. ${ }^{[58]}$ reported that both MRA and CTA are consistent in the measurement of diameters, but MRA is less reliable in the assessment of the lateral position of the BA, which can be explained by the rather indeterminate definition in the MRI criteria. In addition, luminal thrombus was detected equally well by CTA and MRA. CT was advantageous in detecting small calcifications and MRI is superior to CT in detecting perifocal brainstem edema.

\section{Other diagnostic methods}

Other imaging technologies are also being applied to the diagnosis or assisted diagnosis of VBD [6, $31,59,60]$. For instance, ultrasound as an accessory tool helps interpretation of the hemodynamic changes [3]. Digital subtraction angiography (DSA) has been the gold standard for the diagnosis of cerebrovascular disease. Although it incurs relatively large trauma, the operation is risky, and patient selection is limited, it clearly displays lesions and can also be used as a therapeutic means, providing advantages that cannot be replaced by other methods $[59,60]$.

\section{Treatment strategies}

VBD predominantly occurs in deep parts of the brain. Because many of the lesions are located throughout the full length of vertebrobasilar arteries where many important blood vessels are issued, effective treatment remains very difficult. For VBD it- 
self, there is currently no precise and effective treatment, and available treatments mainly target selected symptoms or VBD complications [1, 25, 31,39].

\section{Surgical treatment}

Although there is no precise and effective treatment for VBD, surgical treatment remains most promising. When VBD occurs, the full length of basilar arteries and vertebral arteries undergo tortuous expansion. From a theoretical point of view, removal of the expanded arteries and replacement with new blood vessels that are consistent with the vertebrobasilar branches seems to be the most ideal approach. However, in practice, it is difficult to achieve from the perspective of current technology. Nevertheless, some surgical attempts are still being performed in clinical practice (table 1).

\section{Microsurgical Treatment (table I)}

(1) Changing hemodynamics: Nakatomi et al. suggested that VBD expansion progresses over time and experiences cycles of "internal elastic layer fragmentation $\rightarrow$ intimal hyperplasia neovascularization $\rightarrow$ intramural hemorrhage and thrombosis $\rightarrow$ recanalization in thrombus and recurring hemorrhage". Recurring hemorrhage in the vessel wall is an important step in the growth cycle [8]. Endothelial hyperplasia with significantly enhanced neovascularization is expressed as thickened vessel walls in MRI. Once this imaging is present, surgical intervention should be undertaken to avoid VBD progression. Matsumoto et al. reported two cases of remission from compression symptoms by reducing the blood flow pressure in the posterior circulation. In one case, the right-side blood supply of the vertebral artery was blocked via craniotomy. In the other case, the patient presented with bilateral carotid artery occlusion combined with VBD, and blood flow of the posterior circulation supplied forward to the anterior circulation through bilateral posterior communicating arteries. The patient was given the bilateral superficial temporal artery and middle cerebral artery anastomosis (STA-MCA) to re-construct anterior blood flow. Both patients showed shrinkage of the expanded arteries at the 6-month and 10-month DSA follow-ups respectively, suggesting that hemodynamic factors play an important role in VBD progression [61]. However, this method is also disputed. For instance, O'Shaughnessy et al. reported a VBD patient who had continued growth of the expanded arteries even after blocking bilateral vertebral arteries ${ }^{[62]}$. This also indicates that VBD progression may be dependent on hemodynamic factors as well as result from the cooperation of multiple factors, including neovascularization in the expanded adventitia, double-sandwich progressive growth, repeated vessel wall hemorrhage, tissue growth factors, and elastases [63-65].

(2) Direct surgical treatment: Relevant reports regarding direct surgical treatment are less common. Anson et al. reported a surgical treatment study on a group of 40 patients with dolichoectatic and fusiform aneurysms [25], with 12 of them diagnosed with VBD. Among these VBD patients, three were given thrombotic resection and aneurysm suture (in one case the surgery was assisted with hypothermic cardiac arrest); one was given a combination of auxiliary hypothermic cardiac arrest, thrombectomy, aneurysm suture, and proximal occlusion of blood supply to the vertebral artery; one was given superficial temporal artery and superior cerebellar artery bypass with proximal occlusion; one was given superficial temporal artery and superior cerebellar artery bypass plus distal basilar artery occlusion and thrombectomy; one was given thrombectomy and basilar artery compression under auxiliary hypothermic cardiac arrest; one was given simple proximal occlusion of blood supply to vertebral artery; two cases were given mobilization and transposition; and two cases were given the conservative anticoagulant treatment. Three patients suffered from low cranial nerve palsy after surgery and one patient presented with cerebellar

Table I Microsurgical Treatment of Vertebrobasilar Dolichoectasia. (Changing hemodynamics[61, 62] or Direct surgical treatment[8, 25])

\begin{tabular}{|c|c|c|c|c|c|}
\hline Author & Year & $\begin{array}{l}\text { Number of } \\
\text { Patients }\end{array}$ & Complications & Length of follow-up & Outcome \\
\hline Matsumoto et al.[61] & 1990 & 2 & No & 6-10 months & $\begin{array}{l}\text { Good (symptoms alleviated, reduced } \\
\text { size of dolichoectasia of the basilar } \\
\text { artery) }\end{array}$ \\
\hline Anson et al.[25] & 1996 & 12 & $\begin{array}{l}\text { Lower cranial nerve deficit, postopera- } \\
\text { tive hematomas, subclavian vein } \\
\text { thrombosis, cerebrospinal }\end{array}$ & $0.1-4.7$ years & $\begin{array}{l}4 \text { patients recovered well, } 4 \text { patients } \\
\text { had moderate disability, } 4 \text { patients } \\
\text { had severe disability, and } 4 \text { patients } \\
\text { died. }\end{array}$ \\
\hline O'Shaughnessy et al..$^{[62]}$ & 2004 & 1 & $\begin{array}{l}\text { Thrombosis of distal basilar artery and } \\
\text { pontine infarction }\end{array}$ & 27 months & Death \\
\hline
\end{tabular}


artery occlusion. The follow-up period for the 12 patients varied from 0.1 to 4.7 years with an average of 2.1 years. Twenty-five percent of patients recovered well (GOS score 1 point), $25 \%$ of patients had moderate disability (GOS score 2 points), 25\% of patients had severe disability (GOS score 3 points), and $25 \%$ of patients died (GOS score 5 points). Thus, it is obvious that high risks exist in direct surgical treatment. In a series of 12 cases with intracranial fusiform aneurysm reported by Nakatomi et al.[8], one symptomatic patient and two asymptomatic patients had clip reconstruction of the parent artery. The aneurysms disappeared in the two asymptomatic cases, and no recurrences have been observed. However, the symptomatic patient died of cerebellomedullary infarction after surgery. Histological examination of aneurysm tissues obtained during surgery or autopsy show that internal elastic lamina fragmentation was found in all cases, and intramural hemorrhage (IMH) that can be detected by MRI or CT is the most critical event of aneurysm progress. Four patients who were observed with IMH without surgical intervention or with only a distal bypass showed aneurysm growth without exception. Therefore, appropriate surgical procedures should help patients by preventing progression of the aneurysm.

\section{Endovascular Interventional Treatment (table 2)}

(1)Flow diversion technology: Flow diversion technology refers to the placement of stents in aneurysm-bearing arteries in order to reduce blood flow into the aneurysm and form venous stasis, which leads to gradual thrombosis and neointimal coverage, but the normal functioning of the surrounding arteries and perforating arteries is maintained [66-70]. Currently, the flow diverter devices approved for clinical use include the Pipeline Embolization Device (PED) and the SILK Flow Diverter (SFD). Compared to conventional stents, these stents have smaller mesh and greater metal coverage area, which ensures normal blood flow in branch vessels and perforating arteries but greatly reduces blood flow into the aneurysm cavity. Pumar et al. [67] used SFD to treat a case of giant basilar artery fusiform aneurysm. The aneurysm-related symptoms disappeared completely after the treatment. Six months later, DSA examination showed no development of aneurysm and the basilar artery was anatomically reconstructed whereas branching arteries were preserved. Fiorella et al.[66] used PED to treat a patient with a $4 \mathrm{~cm}$-diameter giant basilar artery stem aneurysm. Seven days after surgery, angiography showed full anatomical reconstruction of the basilar artery and no presence of aneurysm. Again, the branching vessels were unaffected. The patient remained in good condition during 6-month followed-up. Tan et al. ${ }^{[70]}$ reported the use of six PEDs deployed in a telescoping fashion successfully treated a patient with a ruptured vertebrobasilar fusiform aneurysm who presented with subarachnoid hemorrhage (SAH). Conventional cerebral angiogram at six months demonstrated successful reconstruction of the vertebrobasilar system and thrombosis of the aneurysm, and the patient remained neurologically well and was living independently. However, Siddiqui et al. ${ }^{[68]}$ treated seven patients with vertebrobasilar fusiform aneurysms using flow diversion technology. In six cases, PED was used and in one case SFD was used. After surgery, 4 patients (57.1\%) died (2 patients died from aneurysm rupture and 2 patients gave up treatment due to brainstem infarction). The modified Rankin Scale (mRS) scores for the remaining three cases were 5 (severe disability), 1 , and 0 , respectively. The incidence of postoperative cerebral infarction was 5/7 (71.4\%). In consideration of this study, we suggest that more caution should be taken regarding the use of flow diversion technology in treating posterior circulation aneurysms.

Table 2 Endovascular Interventional Treatment of Vertebrobasilar Dolichoectasia. (Flow diversion technology[66-68, 70] and overlapping stent or coil-assisted stent reconstruction[71-76])

\begin{tabular}{|c|c|c|c|c|c|}
\hline Author & Year & $\begin{array}{l}\text { Number of } \\
\text { Patients }\end{array}$ & Complications & $\begin{array}{l}\text { Length of } \\
\text { follow-up }\end{array}$ & Outcome \\
\hline $\begin{array}{l}\text { Liebig et } \\
\text { al.[75] }\end{array}$ & 2008 & 2 & No & 6-9 months & Good (Favorable in both patients) \\
\hline $\begin{array}{l}\text { Fiorella et } \\
\text { al.[66] }\end{array}$ & 2009 & 1 & No & 6 months & $\begin{array}{l}\text { Good (The patient remains neurologically normal, angiography showed anatomic reconstruction } \\
\text { of the basilar artery and complete occlusion of the circumferential aneurysm) }\end{array}$ \\
\hline $\begin{array}{l}\text { Pumar et } \\
\text { al.[67] }\end{array}$ & 2010 & 1 & No & 6 months & $\begin{array}{l}\text { Good (The mass effect was largely resolved and the patient showed complete resolution of his } \\
\text { symptoms.) }\end{array}$ \\
\hline $\begin{array}{l}\text { Bain et } \\
\text { al.[72] }\end{array}$ & 2011 & 1 & $\begin{array}{l}\text { Transient worsening of } \\
\text { hemiparesis }\end{array}$ & 4 months & $\begin{array}{l}\text { Good (The patient did not have any further clinical deterioration, cerebral angiogram and MRI } \\
\text { showed progressive thrombosis of the proximal and distal aneurysms.) }\end{array}$ \\
\hline $\begin{array}{l}\text { Siddiqui } e t \\
a l .[68]\end{array}$ & 2012 & 7 & $\begin{array}{l}\text { Focal cerebral ischemia, } \\
\text { brainstem ischemia, } \mathrm{SAH}\end{array}$ & $\begin{array}{l}2 \text { weeks-5 } \\
\text { months }\end{array}$ & $\begin{array}{l}\text { Four patients died (mRS score of } 6 \text { ), the remaining three patients had mRS scores of } 5 \text { (severe } \\
\text { disability), 1, and 0, respectively. }\end{array}$ \\
\hline $\begin{array}{l}\text { Cohen et } \\
\text { al. }[73]\end{array}$ & 2012 & 1 & No & 6 months & Glasgow Outcome Score 4 \\
\hline $\begin{array}{l}\text { Tan et } \\
\text { al.[70] }\end{array}$ & 2013 & 1 & No & 6 months & $\begin{array}{l}\text { Good (Cerebral angiogram demonstrated successful reconstruction of the vertebrobasilar system } \\
\text { and thrombosis of the aneurysm, the patient remained neurologically well and was living inde- } \\
\text { pendently at home.) }\end{array}$ \\
\hline van Oel, et & 2013 & 13 & Brain stem infarction, & 6-72 months & Nine had a good outcomes with adequate aneurysm occlusion and stable size, two of three patients \\
\hline
\end{tabular}




\begin{tabular}{|c|c|c|c|c|c|}
\hline al. .76$]$ & & & basilar thrombosis, $\mathrm{SAH}$ & & $\begin{array}{l}\text { presenting with SAH died, another one became mute after treatment, there was improvement in } \\
\text { two of three patients presenting with symptoms of mass effect, a final patient remained un- } \\
\text { changed. }\end{array}$ \\
\hline $\begin{array}{l}\text { Wu et } \\
\text { al. } .71]\end{array}$ & 2013 & 9 & $\begin{array}{l}\text { Cerebellar hemisphere } \\
\text { infarction and brain stem } \\
\text { infarction }\end{array}$ & $\begin{array}{l}10-26 \\
\text { months }\end{array}$ & $\begin{array}{l}\text { One patient died from brain stem infarction, one patient died suddenly of unknown etiology after } \\
26 \text { months, one patient developed paralysis due to brain stem infarction after one month, and the } \\
\text { remaining seven cases remained in good condition after the surgery. }\end{array}$ \\
\hline $\begin{array}{l}\text { Chen et } \\
\text { al. }{ }^{[74]}\end{array}$ & 2013 & 10 & Stent migration & 3-36 months & One patient died of rebleeding after sole stenting, the remaining 9 patients had good outcome. \\
\hline
\end{tabular}

(2) Overlapping stent or coil-assisted stent reconstruction: Before the prevalence of PED and SFD, overlapping stent or coil-assisted stent reconstruction may be a valuable alternative[71-76], Cohen et al. [73] used four Leo stents and one SFD with the overlapping stent releasing technology to block the blood supply to the vertebral artery and successfully cured a VBD patient. In spite of the initial neurological dysfunction, the patient gradually recovered well. In the six-month CTA follow-up, the aneurysm cavity was significantly reduced. van Oel et al. ${ }^{[76]}$ used flow diverters, stents, and coils to treated 13 cases of fusiform basilar trunk aneurysms. Stents were placed in all 13 patients, two patients had additional flow diverters, and 11 patients had additional coils. Unilateral vertebral artery was sacrificed with coils to decrease flow into the aneurysm in four patients. Of 13 patients, nine had good outcomes, and repeat angiography demonstrated the fusiform aneurysms had adequate occlusion and stable at the follow-up of 6-72 months. In the three patients presenting with $\mathrm{SAH}$, one died of a rebleed 4 weeks later, one other patient died of in-stent thrombosis soon after treatment, and another patient was mute after treatment. There was improvement in two of three patients presenting with symptoms of mass effect during a follow-up of 6 months to 2 years. This method can reduce the use of stent mesh and change hemodynamics, thereby promoting aneurysm thrombosis. Due to the huge size of the VBD aneurysm cavity, there is a lack of support from the peripheral arterial wall. In surgical procedures, multiple stents can be implanted via the overlapping releasing technology to provide structural support for the following SFD implantation. In some cases, releasing multiple overlapping stents may suffice for surgical purposes. If formation of blood stasis or straightening of tortuous blood vessels is not sufficient, implantation of SFD is required and occlusion of dominant arteries can be applied if necessary. Wu et al. ${ }^{[71]}$ used coil-assisted stent reconstruction in the treatment of 9 patients with symptomatic VBD. One patient died from brain stem infarction and one patient developed paralysis due to brain stem infarction after 1 month. However, the remaining seven cases remained in good condition after the surgery. The mean follow-up time for the eight surviving patients was $20.75 \pm 6.9$ months. One patient died suddenly of unknown etiology after 26 months. Of the four patients with dolichoectasia in the anterior circulation, two presented with anterior circulation infarcts. The condition of the remaining five patients was stable, and four patients who received imaging follow-ups showed almost normal morphology of the vertebrobasilar arteries. Chen et al. ${ }^{\text {[74] }}$ reported a series of 10 consecutive cases with large and giant fusiform aneurysms. Five patients had sole stent placement, three patients underwent stent-assisted coiling, and two patients sacrificed the parent arteries with coils at the proximal of vertebral artery. The follow-up time of the 10 patients was 3 to 36 months. The remaining nine patients had good outcomes, except for one patient who died of bleeding again 18 months later. In addition, Liebig et al. ${ }^{[75]}$ treated two cases of large fusiform aneurysms of the vertebrobasilar junction using coil-assisted stent reconstruction and subsequent coil occlusion of one vertebral artery. The follow-up angiography of one patient revealed that the left V4 segment was stably occluded and there was only moderate compaction of the distal part of the intraaneurysmal coil mesh at 5 months, and it remained stable at the 9-month. The half-year follow-up angiograms of the other patient also showed satisfactory results, there was only minor coil compaction in the distal right V4 segment adjacent to the stent. There was no recanalization of the previously thrombosed distal portions of the aneurysm, and the neurologic symptoms of patients remained stable throughout the study period. Bain et al. successfully cured a patient with a fusiform basilar artery aneurysm using a "double-barrel" telescoping stent construct [72]. The placement of parallel stents solved problems such as poor support stability and the shifting of stents caused by the wide aneurysm neck. The patient had good postoperative recovery. At the 4-month follow-up, angiography suggested that the patient developed aneurysm thrombosis and resumed normal distal blood flow. We suggest that the advantage of releasing of overlapping stents can reduce blood flow in the aneurysm cavity, increase forward flow, straighten tortuous vessels, and increase blood supply to branching arteries. The use of antiplatelet drugs after stent implantation can reduce thrombosis and the risk of bleeding is lower compared to using antiplatelet drugs alone. Nevertheless, we emphasize here that the most common complication in this surgery is brain stem infarction, with an incidence rate as 
high as $22.2 \%[71]$, due to occlusion of the branching vessels. This relates to blood flow stasis and thrombus formation caused by the use of stents and coils. The key to reducing the incidence of complications is to gradually change the hemodynamics in VBD. In light of this, staging surgery and minimizing the use of coils should be considered to optimize the surgery.

\section{Treatment of ischemic stroke}

Ischemic stroke is the most common clinical symptom of VBD. Flemming et al. suggested using anticoagulant or antiplatelet drugs to reduce the incidence of recurrent ischemic stroke. The annual ischemic stroke risk for VBD patients is $2.7 \%$ and the risk of recurrent ischemic stroke is $6.7 \%$. The annual bleeding risk is $0.9 \%$, and for some special types of VBD it is $2.3 \%$. Considering that the risk of recurrent ischemic stroke is higher than the risk of bleeding, the use of anticoagulant or antiplatelet drugs can be beneficial ${ }^{[1]}$. Wolfe et al. proposed that the use of warfarin could reduce mortality [77]. Dziewasa et al. emphasized strict blood pressure control in addition to treatment with antithrombotic drugs [5]. However, Passero et al. suggested that VBD-induced ischemic stroke is attributed to a variety of mechanisms, including atherosclerosis, hemodynamics, and the pulling of dilated arteries. Therefore, using antiplatelet or anticoagulant drugs cannot effectively prevent ischemic stroke but does increase the risk of bleeding. Although anticoagulation or antiplatelet therapy has its merits for the acute treatment phase of ischemic stroke, the risks and benefits of this treatment should be carefully weighed [49]. For VBD-induced internal thrombosis, thrombolytic therapy is a possible option. De Georgia et al. reported one patient with VBD-induced thrombosis. The patient presented with recurrent ischemic stroke despite continuous anti-thrombosis treatment. After intravenous thrombolysis treatment, angiography showed almost complete vertebrobasilar recanalization and normal branch vessel perfusion. The patient continued to receive anticoagulant treatment and no ischemic attack occurred. Unfortunately, after two months, the patient died from subarachnoid hemorrhage due to rupture of the dilated basilar artery [48].

\section{Treatment of brainstem and cranial nerve compression}

In $\mathrm{VBD}$, there is no effective treatment of the clinical symptoms caused by brain stem compression. Ubogu et al. reported a case of VBD with compression of the medulla oblongata. For treatment, a plastic tape was passed around the dilated vessel to form a sling with both ends secured by an aneurysm clip. The clip was then sutured to the lateral posterior fossa petrous dura with nylon stitches to release compression on the cervical medullary junction. Six months after surgery, the patient was fully recovered from cranial nerve symptoms, but limb paresis remained. Based on this case, Ubogu et al. emphasized that early recognition and surgical intervention was crucial for prevention of neurological sequelae in symptomatic VBD [78]. A variety of treatments are available to control VBD-induced drug-refractory trigeminal neuralgia and hemifacial spasm, including radiofrequency ablation, gamma-knife, percutaneous balloon compression of the trigeminal nerve, and botulinum toxin injection. Because all compression symptoms in VBD result from the pulsating nerve root compression, the most effective treatment is microvascular decompression $[31,79,80]$. However, Pereira-Filho et al. found that it was practically difficult to insert a pressure-reducing cotton clip, and even if successful, it may continue to cause compression on the nearby nerve roots and thus not achieve full decompression [29]. Goldenberg-Cohen et al. did not recommend microvascular decompression for single cranial nerve neuropathy because the risk of surgery outweighed the benefits [81]. El-Ghandour et al. performed microvascular decompression for $10 \mathrm{VBD}$ patients, and reported that $80 \%$ of the trigeminal neuralgia symptoms and $75 \%$ of the hemifacial spasm symptoms completely remitted. No recurrence was found in an average of 7.8 years of follow-up. In addition, compared to the reposition and fixation surgery, the microvascular decompression operation was relatively easy with low technical requirements and incurs fewer complications [31].

\section{Treatment of hemorrhage}

Nearly all VBD-caused subarachnoid hemorrhages are fatal and there is no effective treatment. Therefore, the key is to prevent bleeding $[1,8,28,48,49,51$, $52,82]$. However, there is currently no accurate method to predict VBD-related bleeding. In VBD patients, bleeding is often associated with VBD expansion and growth rate, long-term hypertension, and the use of anticoagulant and antiplatelet drugs $[48,49,51,52]$. New ischemic symptoms may also indicate bleeding [28]. Therefore, for patients with VBD, close follow-up and strict control of blood pressure are required, and anticoagulant and antiplatelet drugs should be used with caution. Once VBD progression occurs, prompt surgical intervention is necessary $[8,48,49]$.

\section{Treatment of hydrocephalus}

VBD-induced hydrocephalus is predominantly obstructive, and ventriculo-peritoneal shunt can achieve satisfactory results. Prior to surgery, the location of obstruction must be determined. For hydrocephalus caused by obstruction in the bilateral foramina of Monro, the double lateral peritoneal shunt 
is appropriate [83]. For third ventricle- or midbrain aqueduct-caused hydrocephalus, a unilateral ventriculo-peritoneal shunt is sufficient [43,45]. Oertel et al. reported endoscopic third ventricle fistula treatment in three VBD patients with obstructive hydrocephalus, which achieved good therapeutic results. This method could be potentially applied to treat VBD-induced hydrocephalus [84]. It has been reported in the literature that basilar artery aneurysm ventriculo-peritoneal shunt induced aneurysm rupture or growth $[83,85,86]$. Theoretically, the same situation may also exist in VBD hydrocephalus after ventriculo-peritoneal shunt.

\section{Perspective}

VBD is a complex progressive arterial disease whose pathogenesis needs further investigation. It has complex clinical manifestations, poor prognosis, and a median survival of only 7.8 years [1]. The most common cause of death in VBD is ischemia, but excessive anticoagulation treatment may result in fatal bleeding risks. The development and advancement of dense mesh stent technology may solve this dilemma. The combination of stent construction and anticoagulant therapy may lower the risk of artery rupture and bleeding compared to anticoagulant or antiplatelet therapy alone. Stent construction can reduce the cavity of VBD aneurysm, thereby mitigating the mass effects of $\mathrm{VBD}$, including cranial nerve compression and hydrocephalus, and thus deserves further clinical validation.

\section{Competing Interests}

The authors have declared that no competing interest exists.

\section{References}

1. Flemming KD, Wiebers DO, Brown RD, Jr., et al. The natural history of radiographically defined vertebrobasilar nonsaccular intracranial aneurysms. Cerebrovascular Diseases. 2005;20:270-9.

2. Ince B, Petty GW, Brown RD, Jr., Chu CP, Sicks JD, Whisnant JP. Dolichoectasia of the intracranial arteries in patients with first ischemic stroke: a population-based study. Neurology. 1998;50:1694-8

3. Kumral E, Kisabay A, Atac C, Kaya C, Calli C. The mechanism of ischemic stroke in patients with dolichoectatic basilar artery. European journal of neurology: The Official Journal of the European Federation of Neurological Societies. 2005;12:437-44.

4. Ikeda K, Nakamura Y, Hirayama T, et al. Cardiovascular risk and neuroradiological profiles in asymptomatic vertebrobasilar dolichoectasia. Cerebrovascular Diseases. 2010;30:23-8.

5. Dziewasa R, Freund M, Ludemann P, et al. Treatment options in vertebrobasilar dolichoectasia--case report and review of the literature. European neurology. 2003;49:245-7.

6. Lou M, Caplan LR. Vertebrobasilar dilatative arteriopathy (dolichoectasia). Annals of the New York Academy of Sciences. 2010;1184:121-33.

7. Hegedus K. Ectasia of the basilar artery with special reference to possible pathogenesis. Surgical Neurology. 1985;24:463-9.

8. Nakatomi H, Segawa H, Kurata A, et al. Clinicopathological study of intracranial fusiform and dolichoectatic aneurysms : insight on the mechanism of growth. Stroke; A Journal of Cerebral Circulation. 2000;31:896-900.

9. Pico F, Labreuche J, Touboul PJ, Amarenco P, Investigators G. Intracranial arterial dolichoectasia and its relation with atherosclerosis and stroke subtype. Neurology. 2003;61:1736-42.

10. Gupta D, George UB, Pandian JD. Vertebrobasilar dolichoectasia and a tale of two brothers. Neurology India. 2010;58:810-2.
11. Schievink WI, Torres VE, Wiebers DO, Huston J, 3rd. Intracranial arterial dolichoectasia in autosomal dominant polycystic kidney disease. Journal of the American Society of Nephrology : JASN. 1997;8:1298-303.

12. Laforet $P$, Petiot $P$, Nicolino $M$, et al. Dilative arteriopathy and basilar artery dolichoectasia complicating late-onset Pompe disease. Neurology. 2008;70:2063-6.

13. Garzuly F, Marodi L, Erdos M, et al. Megadolichobasilar anomaly with thrombosis in a family with Fabry's disease and a novel mutation in the alpha-galactosidase A gene. Brain: A Journal of Neurology. 2005;128:2078-83.

14. Steen RG, Langston JW, Ogg RJ, Manci E, Mulhern RK, Wang W. Ectasia of the basilar artery in children with sickle cell disease: relationship to hematocrit and psychometric measures. Journal of Stroke and Cerebrovascular Diseases : The Official Journal of National Stroke Association. 1998;7:32-43.

15. Hainsworth PJ, Mendelow AD. Giant intracranial aneurysm associated with Marfan's syndrome: a case report. Journal of Neurology, Neurosurgery, and Psychiatry. 1991;54:471-2.

16. Kim HS, Choi $\mathrm{CH}$, Lee TH, Kim SP. Fusiform aneurysm presenting with cervical radiculopathy in ehlers-danlos syndrome. Journal of Korean Neurosurgical Society. 2010;48:528-31.

17. Baccin CE, Krings T, Alvarez H, Ozanne A, Lasjaunias PL. A report of two cases with dolichosegmental intracranial arteries as a new feature of PHACES syndrome. Child's Nervous System: Official Journal of the International Society for Pediatric Neurosurgery. 2007;23:559-67.

18. Khan N, Schinzel A, Shuknecht B, Baumann F, Ostergaard JR, Yonekawa Y. Moyamoya angiopathy with dolichoectatic internal carotid arteries, patent ductus arteriosus and pupillary dysfunction: a new genetic syndrome? European Neurology. 2004;51:72-7.

19. Dalton CM, Jager HR, Losseff NA, Greenwood RJ. Varicella zoster virus and intracranial dolichoectasia in a late adult cancer survivor. BMJ Case Reports. 2009;2009:bcr2007120725.

20. Mahadevan A, Tagore R, Siddappa NB, et al. Giant serpentine aneurysm of vertebrobasilar artery mimicking dolichoectasia--an unusual complication of pediatric AIDS. Report of a case with review of the literature. Clin Neuropathol. 2008;27:37-52

21. Lodder J, Vles JS, Broekman JM. Megadolicho anomaly of the basilar artery caused by syphilis (a case report). Clinical Neurology and Neurosurgery. 1982;84:255-9.

22. Pico F, Jacob MP, Labreuche J, et al. Matrix metalloproteinase- 3 and intracranial arterial dolichoectasia. Annals of Neurology. 2010;67:508-15.

23. Toyoshima Y, Emura I, Umeda Y, Fujita N, Kakita A, Takahashi H. Vertebral basilar system dolichoectasia with marked infiltration of IgG4-containing plasma cells: a manifestation of IgG4-related disease? Neuropathology : Official Journal of the Japanese Society of Neuropathology. 2012;32:100-4.

24. Mizutani T, Aruga T. "Dolichoectatic" intracranial vertebrobasilar dissecting aneurysm. Neurosurgery. 1992;31:765.

25. Anson JA, Lawton MT, Spetzler RF. Characteristics and surgical treatment of dolichoectatic and fusiform aneurysms. Journal of Neurosurgery. 1996;84:185-93.

26. Kawahara I, Morofuji Y, Takahata H, et al. Dolichoectasic anterior cerebral artery and hemodynamics. Journal of Stroke and Cerebrovascular diseases: The Official Journal of National Stroke Association. 2012;21:907 e5-8.

27. Passero SG, Rossi S. Natural history of vertebrobasilar dolichoectasia. Neurology. 2008;70:66-72.

28. Flemming KD, Josephs K, Wijdicks EF. Enlarging vertebrobasilar dolichoectasia with subarachnoid hemorrhage heralded by recurrent ischemia. Case illustration. Journal of Neurosurgery. 2000;92:504.

29. Pereira-Filho A, Faria M, Bleil C, Kraemer JL. Brainstem compression syndrome caused by vertebrobasilar dolichoectasia: microvascular repositioning technique. Arquivos de Neuro-Psiquiatria. 2008;66:408-11.

30. Gizewski ER, Spitthover RM, Wiedemayer H, Wanke I, Philipp T, Forsting M. Recurrent neurovascular hypertension: MR findings before and after surgical treatments. AJNR American Journal of Neuroradiology. 2001;22:1168-70.

31. El-Ghandour NM. Microvascular decompression in the treatment of trigeminal neuralgia caused by vertebrobasilar ectasia. Neurosurgery. 2010;67:330-7.

32. Passero S, Rossi S, Giannini F, Nuti D. Brain-stem compression in vertebrobasilar dolichoectasia. A multimodal electrophysiological study. Clinical neurophysiology: Official Journal of the International Federation of Clinical Neurophysiology. 2001;112:1531-9.

33. Jamjoom AB, Rawlinson JN, Coakham HB. Multiple neurological lesions due to vertebrobasilar dolichoectasia. Br J Neurosurg. 1990;4:147-54.

34. Yang XS, Li ST, Zhong J, et al. Microvascular decompression on patients with trigeminal neuralgia caused by ectatic vertebrobasilar artery complex: technique notes. Acta Neurochirurgica. 2012;154:793-7; discussion 97.

35. Niwa Y, Shiotani M, Karasawa H, Ohseto K, Naganuma Y. Trigeminal neuralgia caused by tortuous vertebrobasilar system--the clinical and imaging features. Rinsho Shinkeigaku (Clinical Neurology). 1997:37:191-7.

36. Giray S, Pelit A, Kizilkilic O, Karatas M. Isolated abducens nerve palsy caused by contralateral vertebral artery dolichoectasia. Neurology India. 2005;53:246-7.

37. Maranhao-Filho P, Souto AA, Nogueira J. Isolated Pathetick nerve paresis by compression from a dolichoectatic basilar artery: case report. Arquivos de Neuro-Psiquiatria. 2007;65:176-8.

38. Lin JY, Lin SY, Wu JI, Wang IH. Optic neuropathy and sixth cranial nerve palsy caused by compression from a dolichoectatic basilar artery. Journal of 
Neuro-ophthalmology : The Official Journal of the North American Neuro-Ophthalmology Society. 2006;26:190-1.

39. Jacobson DM, Corbett JJ. Downbeat nystagmus and dolichoectasia of the vertebrobasilar artery. Journal of Neuro-ophthalmology: The Official Journal of the North American Neuro-Ophthalmology Society. 2002;22:150-1; author reply 51.

40. Titlic M, Tonkic A, Jukic I, Buca A, Kolic K, Batinic T. Tinnitus caused by vertebrobasilar dolichoectasia. Bratislavske Lekarske Listy. 2007;108:455-7.

41. Panda S, Goyal V, Gupta V, et al. Vertebrobasilar dolichoectasia presenting as lower cranial nerve palsy. Neurology India. 2004;52:279

42. Madhugiri VS, Roopesh Kumar VR, Gopalakrishnan MS, Shankar Ganesh CV, Sudheer Kumar G. Cranial polyneuropathy associated with vertebrobasilar dolichoectasia. Clinical Neurology and Neurosurgery. 2012;114:1059-61.

43. Siddiqui A, Chew NS, Miszkiel K. Vertebrobasilar dolichoectasia: a rare cause of obstructive hydrocephalus: case report. The British Journal of Radiology. 2008;81:e123-6.

44. Kansal R, Mahore A, Dange N, Kukreja S. Dolichoectasia of vertebrobasilar arteries as a cause of hydrocephalus. Journal of Neurosciences in Rural Practice. 2011;2:62-4.

45. Thiex R, Mull M. Basilar megadolicho trunk causing obstructive hydrocephalus at the foramina of Monro. Surgical Neurology. 2006;65:199-201.

46. Rozario RA, Levine HL, Scott RM. Obstructive hydrocephalus secondary to an ectatic basilar artery. Surgical Neurology. 1978;9:31-4.

47. Breig A, Ekbom K, Greitz T, Kugelberg E. Hydrocephalus due to elongated basilar artery. A new clinicoradiological syndrome. Lancet. 1967;1:874-75.

48. De Georgia M, Belden J, Pao L, Pessin M, Kwan E, Caplan L. Thrombus in vertebrobasilar dolichoectatic artery treated with intravenous urokinase. Cerebrovascular Diseases. 1999;9:28-33.

49. Passero SG, Calchetti B, Bartalini S. Intracranial bleeding in patients with vertebrobasilar dolichoectasia. Stroke; A Journal of Cerebral Circulation. 2005;36:1421-5.

50. Yamaguchi S, Ito O, Maeda Y, et al. Coil embolization for a ruptured posterior cerebral artery aneurysm with vertebrobasilar dolichoectasia. Neurologia Medico-Chirurgica. 2011;51:657-60.

51. Rabb CH, Barnwell SL. Catastrophic subarachnoid hemorrhage resulting from ruptured vertebrobasilar dolichoectasia: case report. Neurosurgery. 1998;42:379-82.

52. Idbaih A, Pico F, Guichard JP, Bousser MG, Chabriat H. Clinical course and MRI changes of basilar artery dolichoectasia: three case reports. Cerebrovascular Diseases. 2004;17:262-4.

53. Staikov IN, Mattle HP. Vertebrobasilar dolichoectasia and exertional headache. Journal of Neurology, neurosurgery, and Psychiatry. 1994;57:1544.

54. Deng D, Cheng FB, Zhang Y, Zhou HW, Feng Y, Feng JC. Morphological analysis of the vertebral and basilar arteries in the Chinese population provides greater diagnostic accuracy of vertebrobasilar dolichoectasia and reveals gender differences. Surgical and Radiologic Anatomy 2012;34:645-50.

55. Smoker WR, Price MJ, Keyes WD, Corbett JJ, Gentry LR. High-resolution computed tomography of the basilar artery: 1 . Normal size and position. AJNR American Journal of Neuroradiology. 1986;7:55-60.

56. Giang D, Perlin S, Monajati A, Kido D, Hollander J. Vertebrobasilar dolichoectasia: assessment using MR. Neuroradiology. 1988;30:518-23.

57. Ubogu EE, Zaidat OO. Vertebrobasilar dolichoectasia diagnosed by magnetic resonance angiography and risk of stroke and death: a cohort study. Journal of Neurology, Neurosurgery, and psychiatry. 2004;75:22-6.

58. Forster A, Ssozi J, Al-Zghloul M, Brockmann MA, Kerl HU, Groden C. A Comparison of CT/CT Angiography and MRI/MR Angiography for Imaging of Vertebrobasilar Dolichoectasia. Clinical Neuroradiology. 2013.

59. Vieco PT, Maurin EE, 3rd, Gross CE. Vertebrobasilar dolichoectasia: evaluation with CT angiography. AJNR American Journal of Neuroradiology. 1997;18:1385-8.

60. Titlic M, Tonkic A, Jukic I, Kolic K, Dolic K. Clinical manifestations of vertebrobasilar dolichoectasia. Bratislavske Lekarske Listy. 2008;109:528-30.

61. Matsumoto K, Yamada K, Hayakawa T, et al. Dolichoectatic basilar artery treated by reducing hemodynamic stress--report of two cases. Neurologia Medico-Chirurgica. 1990;30:691-4.

62. O'Shaughnessy BA, Getch CC, Bendok BR, Parkinson RJ, Batjer HH. Progressive Growth of a Giant Dolichoectatic Vertebrobasilar Artery Aneurysm after Complete Hunterian Occlusion of the Posterior Circulation: Case Report. Neurosurgery. 2004:55:1223.

63. Iihara K, Murao K, Sakai N, et al. Continued growth of and increased symptoms from a thrombosed giant aneurysm of the vertebral artery after complete endovascular occlusion and trapping: the role of vasa vasorum. Case report. Journal of Neurosurgery. 2003;98:407-13.

64. Mount LA, Taveras JM. Ligation of basilar artery in treatment of an aneurysm at the basilar-artery bifurcation. Journal of Neurosurgery. 1962;19:167-70.

65. Mizutani T. A fatal, chronically growing basilar artery: a new type of dissecting aneurysm. Journal of Neurosurgery. 1996;84:962-71.

66. Fiorella D, Kelly ME, Albuquerque FC, Nelson PK. Curative reconstruction of a giant midbasilar trunk aneurysm with the pipeline embolization device. Neurosurgery. 2009;64:212-7; discussion 17.

67. Pumar JM, Garcia-Dorrego R, Nieto A, Vazquez-Herrero F, Blanco-Ulla M, Vazquez-Martin A. Vascular reconstruction of a fusiform basilar aneurysm with the Silk embolization system. Journal of Neurointerventional Surgery. 2010;2:242-4.
68. Siddiqui AH, Abla AA, Kan P, et al. Panacea or problem: flow diverters in the treatment of symptomatic large or giant fusiform vertebrobasilar aneurysms. Journal of Neurosurgery. 2012;116:1258-66.

69. Wong GK, Kwan MC, Ng RY, Yu SC, Poon WS. Flow diverters for treatment of intracranial aneurysms: current status and ongoing clinical trials. Journal of Clinical Neuroscience: Official Journal of the Neurosurgical Society of Australasia. 2011:18:737-40.

70. Tan LA, Moftakhar R, Lopes DK. Treatment of a ruptured vertebrobasilar fusiform aneurysm using pipeline embolization device. Journal of Cerebrovascular and Endovascular Neurosurgery. 2013;15:30-3.

71. Wu X, Xu Y, Hong B, Zhao WY, Huang QH, Liu JM. Endovascular reconstruction for treatment of vertebrobasilar dolichoectasia: long-term outcomes. AJNR American Journal of Neuroradiology. 2013;34:583-8.

72. Bain M, Hussain MS, Spiotta A, Gonugunta V, Moskowitz S, Gupta R. "Double-barrel" stent reconstruction of a symptomatic fusiform basilar artery aneurysm: case report. Neurosurgery. 2011;68:E1491-6; discussion E96.

73. Cohen JE, Gomori JM, Moscovici S, Itshayek E. Successful endovascular treatment of a growing megadolichoectasic vertebrobasilar artery aneurysm by flow diversion using the "diverter-in-stent" technique. Journal of Clinical Neuroscience: Official Journal of the Neurosurgical Society of Australasia. 2012;19:166-70

74. Chen Z, Yang Y, Miao H, et al. Endovascular treatment for large and giant fusiform aneurysms of the vertebrobasilar arteries. Clinical Imaging. 2013:37:227-31

75. Liebig T, Henkes H. Re and Deconstruction: Staged Treatment of Large Fusiform Aneurysms of the Vertebrobasilar Junction by Stent Deployment and Subsequent Coil Occlusion of One Vertebral Artery. Clinical Neuroradiology-klinische Neuroradiologie. 2008.

76. van Oel LI, van Rooij WJ, Sluzewski M, Beute GN, Lohle PN, Peluso JP. Reconstructive endovascular treatment of fusiform and dissecting basilar trunk aneurysms with flow diverters, stents, and coils. AJNR American Journal of Neuroradiology. 2013;34:589-95.

77. Wolfe T, Ubogu EE, Fernandes-Filho JA, Zaidat OO. Predictors of clinical outcome and mortality in vertebrobasilar dolichoectasia diagnosed by magnetic resonance angiography. Journal of Stroke and Cerebrovascular Diseases: The Official Journal of National Stroke Association. 2008;17:388-93.

78. Ubogu EE, Chase CM, Verrees MA, Metzger AK, Zaidat OO. Cervicomedullary junction compression caused by vertebral artery dolichoectasia and requiring surgical treatment. Case report. Journal of Neurosurgery. 2002;96:140-3.

79. Kraemer JL, Pereira Filho Ade A, David G, Faria Mde B. Vertebrobasilar dolichoectasia as a cause of trigeminal neuralgia: the role of microvascular decompression. Case report. Arquivos de Neuro-Psiquiatria. 2006;64:128-31.

80. Rahman EA, Trobe JD, Gebarski SS. Hemifacial spasm caused by vertebral artery dolichoectasia. American Journal of Ophthalmology. 2002;133:854-6.

81. Goldenberg-Cohen N, Miller NR. Noninvasive neuroimaging of basilar artery dolichoectasia in a patient with an isolated abducens nerve paresis. American Journal of Ophthalmology. 2004:137:365-7.

82. Kubis N, Mikol J, Von Langsdorff D, et al. Dolichoectatic basilar artery: subarachnoid hemorrhage is not so rare. Cerebrovascular Diseases. 2003;16:292-5.

83. Goetz C, Seifert V, Haubitz B. The foramen of Monro--blockage caused by a giant aneurysm of the basilar artery. A case report and review of the literature. Neurochirurgia. 1990;33:122-6.

84. Oertel JM, Mondorf Y, Gaab MR. Endoscopic third ventriculostomy in obstructive hydrocephalus due to giant basilar artery aneurysm. Journal of Neurosurgery. 2009;110:14-8.

85. Hongo K, Morota N, Watabe T, Isobe M, Nakagawa H. Giant basilar bifurcation aneurysm presenting as a third ventricular mass with unilateral obstructive hydrocephalus: case report. Journal of Clinical Neuroscience: Official Journal of the Neurosurgical Society of Australasia. 2001;8:51-4.

86. Kim MS, Oh CW, Han DH. Growth of basilar artery aneurysm after ventriculo-peritoneal shunt. Journal of Clinical Neuroscience: Official Journal of the Neurosurgical Society of Australasia. 2002;9:696-702. 